\title{
Probable association between increased systemic recurrence and the use of scalp cooling in breast cancer patients receiving (neo) adjuvant chemotherapy
}

\author{
Kadri Altundag ${ }^{1}$ (D) \\ Received: 11 May 2020 / Accepted: 7 July 2020 / Published online: 14 July 2020 \\ (C) Springer-Verlag GmbH Germany, part of Springer Nature 2020
}

To the Editor,

I wish to congratulate Ohsumi and colleagues for their article [1] in which they investigated the effects of scalp cooling for hair loss prevention in female Japanese breast cancer patients receiving (neo)adjuvant chemotherapy. They reported that the efficacy of scalp cooling during chemotherapy infusion for hair loss prevention in Asian women is similar to that in Caucasian women. Rugo and colleagues [2] evaluated the effect of scalp cooling versus no scalp cooling on the risk of scalp metastasis in patients treated for breast cancer with chemotherapy. Their systematic review and meta-analysis suggested that scalp cooling does not increase the incidence of scalp metastases. However, a common issue in scalp cooling during chemotherapy may be the concern of increased systemic recurrence other than concentrating on the incidence of scalp metastases. Various clinical studies involving the enumeration of circulating tumor cells (CTCs) in breast cancer patients have unequivocally showed the prognostic value of these cells. Recent molecular studies indicated that CTCs may be potential surrogate markers for systemic disease [3]. Scalp cooling, in addition to leading to less hair loss in early-stage breast cancer patients, may also protect circulating tumor cells (CTCs) which might be the responsible cells for systemic recurrence located in the scalp vasculature from chemotherapy through vasoconstriction resulting in reduced blood flow and reduced metabolic rate in the scalp. Then, protected CTCs may disseminate to other common metastatic sites in breast cancer patients. Taken all together, long- term survival data are needed to validate comfortable use of scalp cooling especially in high-risk early breast cancer patients [4].

\section{Compliance with ethical standards}

Conflict of interest The author declares that he has no conflict of interest.

\section{References}

1. Ohsumi S, Kiyoto S, Takahashi M, Hara F, Takashima S, Aogi K, Matsuda M, Yamamura N, Doi M (2020) Scalp cooling for hair loss prevention in female Japanese breast cancer patients receiving (neo)adjuvant chemotherapy. Support Care Cancer. https://doi.org/ 10.1007/s00520-020-05506-w

2. Rugo HS, Melin SA, Voigt J (2017) Scalp cooling with adjuvant/ neoadjuvant chemotherapy for breast cancer and the risk of scalp metastases: systematic review and meta-analysis. Breast Cancer Res Treat 163:199-205

3. Lee JS, Magbanua MJ, Park JW (2016) Circulating tumor cells in breast cancer: applications in personalized medicine. Breast Cancer Res Treat 160:411-424

4. Altundag K (2017) Do systemic recurrences increase after the use of scalp cooling in patients treated for breast cancer with chemotherapy? J BUON 22:1362-1363

Publisher's note Springer Nature remains neutral with regard to jurisdictional claims in published maps and institutional affiliations.

Kadri Altundag

altundag66@yahoo.com

1 MKA Breast Cancer Clinic, Tepe Prime, Cankaya,

06800 Ankara, Turkey 